\title{
ANAESTHETIC MANAGEMENT OF A 5 MONTH OLD PREMATURE INFANT WITH RESPIRATORY STRIDOR FOR PDA CLOSURE
}

Sushanta Kumar Bhoi1 ${ }^{1}$ Kalyanibala Nayak², Chitralekha Patra ${ }^{3}$, Amiya Kumar Nayak ${ }^{4}$

\section{HOW TO CITE THIS ARTICLE:}

Sushanta Kumar Bhoi, Kalyanibala Nayak, Chitralekha Patra, Amiya Kumar Nayak. "Anaesthetic Management of a 5 Month Old Premature Infant with Respiratory Stridor for PDA Closure". Journal of Evolution of Medical and Dental Sciences 2015; Vol. 4, Issue 64, August 10; Page: 11256-11259, DOI: 10.14260/jemds/2015/1622

ABSTRACT: Management of a premature infant with PDA poses a significant challenge in the perioperative period for the anaesthesiologist. The risk is multiplied when it is associated with other congenital respiratory anomalies. In our case a premature child at 5 month of age presented with PDA and tracheomalacia. There was a risk of airway collapse during sedation or induction of anaesthesia along with an anticipated difficult intubation. We have managed the case by inducing and intubating the patient in the lateral position without using muscle relaxants. We have used Sevoflurane as the sole anaesthetic agent for inducing and intubating the patient. Postoperatively patient was extubated in lateral position and succesfully discharged from ICU.

KEYWORDS: Premature, PDA, Congenital respiratory anomaly, Tracheomalacia, Induction, Intubation, muscle relaxants, Sevoflurane.

INTRODUCTION: Survival of extremely premature infants increased significantly over last two decades due to major medical advances such as surfactant therapy, improved ventilation technique, antenatal administration of steroids and advanced nutritional support. ${ }^{1}$ As a consequence, the incidence of PDA has also increased and has become a very common indication for thoracic surgery in these fragile patients.

Providing anaesthesia for surgical closure of PDA in preterm infants require a through understanding of several consideration. First the precarious physiology of preterm infant increases the risk of aponea, anaemia, hypoglycemia, intraventricular haemorrhage. ${ }^{2}$ It is not rare to diagnose congestive heart faliure in these patients as a result of increased pulmonary blood flow and reduced lung compliance. Furtermore these patients have fragile lungs, are usually intubated and mechanically ventilated putting them at risk of atelactasis and pulmonary infections. Fluid restriction and diuretic therapy are often used as adjunct in the treatment of PDA may be responsible for development of hypovolemia and severe hypotension should inhalational anaesthetic be administered. ${ }^{3}$

Currently there is no general aggrement for the ideal anaesthetic to use for surgical PDA ligation. Previous reports shown that premature infants are especially vulnerable to metabolic and respiratory derangement as result of stress triggered by major operation and anaesthetic technique especially the anaesthetic agents used, have an important impact on perioperative outcome.

CASE REPORT: A 5 month old male child of weight $2.5 \mathrm{~kg}$ presented with chief complains of hurried respirations and noisy breathing for 1 month which has increased in last 5 days. He born by normal vaginal delivery at 28 wks of gestation with birth weight of $1.8 \mathrm{~kg}$. He had hypoxic ischemic encephalopathy during birth. On course of treatment he had 2 episodes of convulsion. On clinical examination it is a IUGR baby with respiratory rate of 48 breaths/min. He had inspiratory stridor with subcostal and sternal indrawing. He had pulse rate of 110/min and blood pressure 90/56 


\section{CASE REPORT}

mmHg. On local examination he had microtia with preauricular skin tags, but rest of the face is normal.

With fine basal crepts found at base. In cardiovascular, there is a continuous machinery murmur over the precordium, radiating to the back with a palpable thrill. S1 is normal and S2 is masked by murmur. His investigation revealed $\mathrm{Hb} 11 \mathrm{gm}$, TLC 11, 400, DC shows lymphocytosis. On chest X-ray features of cardiomegaly and lung congestion present. Echo study revealed PDA of 4mm diameter with left to right shunt with normal biventricular function. Rest of investigation normal. He had received treatment i.e, inj. amphicillin, inj ceftriaxone, inj. lasix, syp dixin, inj fosolin, injvancomycin and 02 inhalation.

As the patient has inspiratory stridor, we suspected for airway anomaly tracheomalacia. As the stridor was relieved in lateral \& prone position. So the final diagnosis is congenital anomalous baby with patent ductus arteriosus and tracheomalacia.

Genaral anaesthesia was planned and informed consent was obtained from patient parent after explaining the risk of surgery and anaesthesia. In the theatre standard monitoring like ECG, pulse oximetry and NIBP attached. A 22G IV cannula was inserted in right foot. Inj fentanyl $10 \mu \mathrm{g}$ was given as analgesic. Then patient was induced with sevoflurane through mapleson $\mathrm{F}$ circuit. Sevoflurane inhalation started at $8 \%$ then decreased to $2 \%$ after loss of consciousness. Direct laryngoscopy was attempted in lateral position in view of suspected tracheomalacia. With $2^{\text {nd }}$ attempt of direct laryngoscopy intubation done with a $3.5 \mathrm{~mm}$ uncuffed tube. After confirming tube position it is fixed at $11 \mathrm{~cm}$ and then inj atracurium.5mg given IV bolus. Anesthesia was maintained with 02: N20 50:50 and sevoflurane inhalation 1-3\% and inj atracurium.1mg intermittently.

Then a 20G arterial cannula introduced into right femoral artery and a $5 \mathrm{Fr}$ central venous catheter inserted into left femoral vein. IV fluid isolyte P started at $5 \mu \mathrm{drop} / \mathrm{min}$. Patient kept in left lateral position and left anterolateral thoracotomy done. Meanwhile during surgery oxygen saturation start dropping to $87 \%$ which may be due to mechanical retraction of lung tissue by the surgeon. So we made Fio2 to $100 \%$ and gave PEEP $5 \mathrm{mmHg}$. So oxygen saturation maintained at $96-$ 98\%. During ligation of PDA systolic blood pressure reduced to $50-60 \mathrm{mmHg}$ by sodium nitroprusside infusion and gradually returned to normal pressure after ligation.

At the end of surgery patient was reversed with inj Atropine $0.1 \mathrm{mg}$ and inj Neostigmine $0.12 \mathrm{mg}$. But patient is not maintaining oxygen saturation on spontaneous breathing with endotracheal tube in situ. On auscultation chest reveals basal crepitations with wheeze. So inj hydrocortisone $25 \mathrm{mg}$, inj derriphyline $0.5 \mathrm{ml} \&$ inj furosemide $5 \mathrm{mg}$ iv given. Baby was warmed by hot air blower. After 15 mins chest finding improved, baby was active and peripheral extremities warm. As we suspected for tracheomalacia extubation also done in lateral position. Post extubation baby was active, warm, maintained 02 saturation, stridor present but decreased in intensity and vitals parameter are stable. So patient was shifted to ICU for observation.

DISCUSSION: PDA is a common congenital cardiac defect in a premature infant. In normal birth weight and full term neonate, the ductus arteriosus closes within 3 days after birth. However the arteriosus is patent more than 3 days after birth in $80 \%$ of preterm neonate weighing $<750 \mathrm{gm}$ and its persistent patency is associated with increased morbidity and mortality. In presence of a significant L- $\mathrm{R}$ shunt in low birth weight, a decreased peripheral perfusion and 02 delivery occurs.

Our patient presented with growth retardation, poor oral feeding and respiratory stridor. This patient have also preauricular skin tags, microtia, abnormal facies. As the patient has respiratory 
stridor we suspect for tracheal anomalies, Tracheomalacia. Difficult intubation is expected in this patient because of facial and tracheal abnormality. ${ }^{4}$ We have done intubation and extubation in lateral position. Also we have used no relaxant technique, intubation done under deep inhalational anaesthesia (Sevoflurane). In these patients, it is crucial to stabilize the heart rate in order to maintain the cardiac output. Sevoflurane is able to do so and that is why this inhalation anaesthetic was the drug of choice in our case.5,6,7 Because of the difficult airway, it is necessary to maintain spontaneous breathing in this patient. Considering the prematurity and low birth weight, Sevoflurane was used for maintainance of anaesthesia because it has a quick recovery time.

Pediatric airway itself and when associated with airway malacia/stenosis in a child with multiple congenital syndrome, have higher incidence of difficult intubation as well as post extubation complication. Hence one should be prepared with the plan for difficult intubation/ventilation and for postoperative consequences.

In intraoperative period oxygen saturation dropped down. It may be due to mechanical retraction of lung tissue and chronic lung congestion. Barotrauma should be avoided as well as excessive 02 concetration predispose for retinopathy of prematurity. Dead space must also be minimised. Positive pressure ventilation should be done to prevent lung exhaustion. If using ventilator it should ideally be able to deliver pressure controlled ventilation with PEEP. ${ }^{8}$ In this case we have used Mapleson-F circuit with 4lit of fresh gas flow.

Since most patients are premature they have significant health problems like postoperative aponea, hypothermia, decreased metabolism of drugs and immature center. ${ }^{9}$ Method of anaesthesia technique can affect the postoperative outcome in these patients. ${ }^{10}$ Our patient in the postoperative period unable to maintain oxygen saturation in spontaneous breathing with endotracheal tube in place. So we manged the situation with inj hydrocortisone, inj furosemide, inj derriphyline and positive pressure ventilation. After 30 mins patient condition improved, respiration became regular, 02 saturation maintained, chest finding improved and baby became warm and active.

\section{REFERENCES:}

1. Rushing S, Ment I.R. Preterm birth: A cost benefit analysis. Semin Perinatol 2004; 6: 444-450

2. Litmann R. The premature infant. In: Litmann R(ed). Pediatric Anaesthesia-The Requisites in Anaesthesiology. 1st edn.Elsevier-Mosby: Philadelphia, 2004, pp73-83.

3. Hickey P, Hansen D. Fentanyl and Sufentanyl- Oxygen- pancuronium Anaesthesia for Cardiac Surgery in Infants. Anaesth Analg 1984; 63: 117-124.

4. Fatemeh Roodneshin, Mahavash Agah. Management of anaesthesia in Goldenher syndrome: case series study, Tanaffois (2009) 8(4), 43-50.

5. Holzman RS, vander Velde ME, Kaus SJ, Body SC, Colan SD, Sullivan LJ, et al. Sevoflurane depresses myocardial contractility less than halothane during induction of anaesthesia in children. Anaesthesiology 1996; 85(6): 1260-7.

6. Kern C, Erb T, et al. Hemodynamic response to sevoflurane compared with halothane during inhalation induction in children. Pediatric anaesthesia 1999; 7: 439-44.

7. Rodrigo MRC, Moles TM, Lee PK. Comparision of the incidence and nature of cardiac arrhythmia occuring during Isoflurane \& Halothane anaesthesia. Br J Anaesth 1986; 58(4): 394400.

8. Baley G, Walker I, Special consideration in premature and ex-premature infants 


\section{CASE REPORT}

9. Larsen WS, Rasmussen LS. The former preterm infant and risk of postoperative aponea: recommendation for management. Acta Anaesthesia.

10. Anaesthetic technique and postoperative outcome in preterm infants undergoing PDA closure. J Pennataly 2010 Oct, 30(10), 677-82.

\section{AUTHORS:}

1. Sushanta Kumar Bhoi

2. Kalyanibala Nayak

3. Chitralekha Patra

4. Amiya Kumar Nayak

\section{PARTICULARS OF CONTRIBUTORS:}

1. Senior Resident, Department of Anaesthesia, SCB Medical College, Cuttack.

2. Associate Professor, Department of Anaesthesia, SCB Medical College, Cuttack.

3. Assistant Professor, Department of Anaesthesia, SCB Medical College, Cuttack.

FINANCIAL OR OTHER COMPETING INTERESTS: None
4. Senior Resident, Department of Anaesthesia, SCB Medical College, Cuttack.

\section{NAME ADDRESS EMAIL ID OF THE} CORRESPONDING AUTHOR:

Dr. Sushanta Kumar Bhoi, C/o. Bidyutlata Swain, At near Bijaya Lodge, Phandi Road, Manglabag, Cuttack, Odisha.

E-mail: bhoisushantakumar@yahoo.com

Date of Submission: 20/07/2015. Date of Peer Review: 21/07/2015. Date of Acceptance: 04/08/2015. Date of Publishing: 10/08/2015. 